\title{
Haunting across the Class Divide: Sarah Waters's Affinity and The Little Stranger
}

\author{
Barbara Klonowska \\ Catholic University of Lublin \\ barbara.klonowska@kul.pl \\ Received 28 February 2017; accepted 3 October 2017.
}

\begin{abstract}
Haunting in literary fiction is often interpreted psychologically as a sign of suppressed psychic content or as nostalgia or mourning for the loss. Yet, it may also be used allegorically as a manifestation of hidden social conflicts, and hence mark a political agenda of thus constructed works. In the novels by Sarah Waters spectres, poltergeists and haunting appear not as a sign of or a contact with an outer reality; to the contrary, they may be seen as perfectly human - though eccentric - expressions of class and economic inferiority. In Affinity spectres and spiritual séances are presented as a means of earning money by lower classes and the latter's cunning use of the upper classes' credulity. In The Little Stranger the poltergeist may be interpreted as an accumulated anger and desire of the servants long ignored by the masters of the emblematic country house. In both, haunting and ghosts manifest vengeance of the underprivileged taken on the socially superior. The essay shows how fictional haunting and spectrality, far from marking a supernatural reality or introducing extrasensory concepts, may function as an allegorical method to discuss political and social problems such as class inequality or social justice.
\end{abstract}

Keywords: haunting; neo-Victorian fiction; class; trauma; suppression; rewriting; political intervention.

\section{Haunting Literature}

In literary texts, the theme of haunting and figures of spectres or ghosts may simultaneously perform several functions. For one, they often appear purely for entertainment purposes, introducing attractive plots and intriguing characters, as in popular ghost stories or in the literature for younger readers, where spectrality often brings little more than suspense and fun. More importantly, however, through drawing attention to supernatural phenomena, literary spectres, ghosts and haunting may lead to the resulting revising and 
expanding of the concept of reality installed by existing philosophical and political systems and shared by the reading public — as is the case, for instance, of magic realist fiction which thus challenges and problematises the received notions of reality, time, space or history. Finally, haunting may also suggest problems suppressed by official discourses, be it private or public, which yet resurface in a spectral form to mark the trace of that which has been silenced and eliminated - as in, for instance, Gothic literature which strongly emphasises culturally suppressed and unwanted notions. In the latter case, spectrality and haunting may be and are often interpreted psychologically, as a literary strategy to mark the processes of suppression and the subsequent return of variously unwanted psychological content. Sexuality, trauma or loss feature prominently in spectral literature, with haunting signalling the return to that which has been suppressed, unrealised, lost or too painful to confront openly. This return, as psychoanalysts suggest, may perform several functions, which range from coming to terms and confrontation with painful experience, through mourning, nostalgia and remembering, to restorative processes. The obsessive return is usually linked by psychologists to trauma and seen as an attempt to work through it via incessant repetition; for Sigmund Freud, as Ankhi Mukherjee suggests, "repetition is a mode of recuperating loss, a ritual of control" (Mukherjee, 2005, p. 109). Spectrality, then, may be seen as an empowering strategy of confronting and dealing with harm and loss. In contrast, the Lacanian interpretation of the compulsive return sees it as "a quest for lost pleasure through symbolic substitution" (Mukherjee, 2005, p. 109) and a symptom of alienation rather than mastery. In both cases, however, trauma and pleasure, control and alienation, seem to mark the extreme poles, with the broad spectrum of possible forms and functions of haunting that lie in between.

One of the relatively less popular and less frequently explored possibilities of interpreting haunting and spectres is to see them as sociological phenomena and social facts, marking and signalling social and political rather than purely psychological phenomena. Yet, as Avery F. Gordon remarks, "haunting is a constituent element of modern social life. It is neither pre-modern superstition nor individual psychosis; it is a generalizable social phenomenon of great import" (1997, p. 7). Thus, apart from its aesthetic, literary or psychological functions, haunting may be also interpreted as a sign or a trace marking social phenomena, and processes operating at a larger scale than the individual psyche. Gordon claims that

the ghost is just the sign, or the empirical evidence. . . that tells you a haunting is taking place; the ghost is not simply a dead or a missing person, but a social figure, and investigating it can lead to that dense site where history and subjectivity make social life. $(1997$, p. 8)

Haunting, then, may be studied as a sociological phenomenon worth analysing on its own terms; yet, it may also be treated as a sign of latent social problems and thus interesting as a mode of investigation leading to the knowledge about the haunted communities and their histories. 
Thus, the literature employing the themes and motifs of haunting or ghostly and spectral figures may be variously analysed for its very diverse aesthetic, psychological or social functions. Haunting and spectrality seem to be employed by contemporary culture to signal a plethora of phenomena and thus may become subjects of numerous subsequent interpretations. The contemporary novel is one of these areas of culture where spectrality seems to be operating vigorously, despite the lasting high reputation of realism or the seeming reluctance of the high-brow novel to treat seriously phenomena that are often classified as parapsychology or superstition. The recent novels by Sarah Waters may serve as an excellent example of an ingenious employment of the theme of haunting, which is used as a vehicle to tackle rather serious and large social problems. This essay will analyse two of her novels, Affinity (1999) and The Little Stranger (2009), to argue that in Waters's fiction, haunting and spectrality appear both as manifestations of suppressed emotions, and as a trace of powerful social conflicts. Haunting, then, on the one hand, for the characters of the novels, functions as a psychological strategy and a method to gratify their particular desires and achieve their secret aims. On the other hand, read from a broader sociological point of view, haunting becomes a spectacular sign of seemingly unseen and yet long-lasting and vigorously operating processes of social hierarchization, and a means of subsequent retribution exacted by the helpless and mistreated. As the subsequent analysis will suggest, Waters's novels construct haunting both negatively, as a sign and trace of social injustice, and positively, as a perverted yet surprisingly effective way of taking revenge on the perpetrators and compensating for the harm done. In so doing, Waters's fiction demonstrates that literary haunting may prove both an aesthetically attractive and politically effective way of returning to the painful social problems undertaken to examine and possibly correct the wrongs of the past.

\section{Haunting as a Ploy}

Both of Waters's novels may be easily classified generically as historical novels since they amply fulfil the criteria enumerated by Avrom Fleishman in his definition of the genre of the historical novel: the distance from the past exceeding that of two generations, the inclusion of recognised historical figures, a plot referring to historical events, particularly those in the public sphere (e.g. wars), specificity and realistic descriptions, the suggestive "feeling" of the times described, a meaning and value, all combined with the literary entourage of genres such as tragedy, comedy, romance and satire (Fleishman, 1971, pp. 3-8). Both Affinity and The Little Stranger, however, treat the traditional structure of the historical novel, on the one hand, as a starting point of the investigation of the past, and on the other, as a means to return to it in a gesture of an imaginary compensation and reparation.

Affinity is a queer romance set in mid-Victorian times, involving ostensibly a middle-class spinster, Margaret Prior, shown as gradually falling in love with and discovering her "affinity" to Selina Dawes, a working-class spirit-medium serving her term in the Millbank prison for women, sentenced for the assault leading to death during a spiritist séance. In the background of this plot, however, another romance is signalled and developed, which in the end turns out much more dramatically vital: that of Selina and her servant-companion, 
Ruth Vigers. Their relationship constitutes the core of the story, and yet, characteristically, it goes unnoticed both by Margaret-the narrator, and by the represented Victorian milieu. This narratorial invisibility and the seemingly small — though, in fact, fundamental - dramatic importance of the romance between a servant and a spirit-medium may be interpreted as reflecting in the plot of the text the social "invisibility" and marginal importance of lower-class figures and their lives. In her diary, the main narrator of the story, Margaret, describes her growing "affinity"; her narratorial point of view is that of an educated and over-sensitive young lady of means, interested in art and science and used to ignoring servants, together with other practicalities of mundane life. Thus, her credulity and blindness, which lead to the dramatic ending of the novel when she discovers the extent of her naivety and her role of the dupe in a deception plot, result only partly from the specific character construction. More broadly, her blindness may be also read as a convenient metonymy of a larger blindness of the privileged and of the social invisibility of lower classes.

The characters representing the lower classes, however, turn out equally important in the plot of the novel as the privileged ones, and haunting and spectres literally become their means of survival. Selina Dawes successfully earns a living as a spirit-medium that gratifies the desires of bereft ladies, hysterical young women and curious gentlemen. With the help of her accomplice, Ruth Vigers, she effectively deceives her clients during séances, gaining the reputation of a gifted medium, which brings financial security and the chance to enjoy the middle-class lifestyle. After her downfall, she resorts to fake haunting again as a method of escaping from prison and fleeing England together with her lover-accomplice. As Susan Alice Fischer observes, "while Margaret has been given more voice and narrative space, the novel ending with Selina's subversive liberation leaves another 'sister' in the darkness of death and opens the reader's eyes to a desperate resistance to a system rooted in class hierarchy" $(2013$, p. 28).

Thus, far from marking any supernatural reality or hinting at the spiritual or psychological, haunting in this novel functions, first, at a purely literal level as an occupation available to lower-class girls, allowing them to make ends meet and - perhaps less typically — get out of prison. Working as a medium-spirit, though seemingly eccentric, was in fact not an uncommon female profession in Victorian England. In her study of neo-Victorian fiction Louisa Hadley observes that most of the registered mediums of this era were women and, following the ground-breaking work by Alex Owen, she shows how, though not unproblematically, "nineteenth-century spiritualism challenged Victorian gender ideologies by granting women power within the spiritual world" (2010, p. 91). Although, as Alex Owen demonstrates, female spiritualism was in fact quite complicit with the Victorian ideals and concepts of femininity, it nevertheless granted women some freedom and a possibility to improve their limited position within the society of that time (Hadley, 2010, p. 87). Haunting, then, though faked, is performed for very pragmatic reasons within Waters's novel: for its characters, it provides a job, a status-improvement, and liberation. The narrative, in turn, employs it not so much to point to the supernatural or psychological; rather, it refers the reader to the social and political, inviting them to consider the position of women in general, and lower-class women in particular. 
Interestingly, however, and in keeping with the frequent interpretation of textual haunting as a sign of repression, in Affinity haunting does, albeit perversely, perform that function, too. It seems to refer the reader back to the repressed or inferior sex (women), class (working class) and sexual orientation (lesbians) and imaginatively not only to present but also to improve their fate. Thus, haunting, although doubly fictional in this novel, does manage to bring back the experience - though not the point of view — of lower class lesbian women and within the narrative, allows them to enjoy a better fate and justice than it was the case in reality. In Waters's novel, then, haunting functions politically as a recuperation of and an imaginary intervention into the past in order to correct its wrongdoings. In this, as Hadley observes, "Waters adopts a Marxist perspective by drawing attention to the position of the lower classes" (2010, p. 89). Textual haunting, used as a ploy by the characters and as a means to improve their social and financial position, at the level of the narrative works to improve, if only imaginatively, the position of lower-class women in the discourses about the past. It offers them - though only textually — an opportunity to present and correct their historical experience.

\section{Haunting as Vengeance}

Yet, both in Affinity and, to a significantly greater extent, in The Little Stranger, haunting may be interpreted not merely sociologically, as a narrative tool to present some social experience, but also psychologically, as a way to convey and express emotions. In the former novel, haunting recuperates the anger of the characters of Ruth Vigers and Selina Dawes and serves as a way to take revenge for years of their social inferiority and neglect. In the latter novel, this is also the case of the character of a working-class physician, Dr Faraday, a seemingly benevolent and well-wishing neighbour of a country-house family who, through subconsciously provoked haunting and visitations, takes revenge for his inferiority on those who for years despised and ignored him and his family. As Emma Parker observes in her insightful and inspiring reading of haunting in this novel, "by presenting . . . a house haunted by a spirit fuelled by envy and anger, The Little Stranger explores the destructive effects of class hierarchy, while also challenging dominant ideologies of gender and sexuality" (2013, p. 112). Thus, the textual haunting functions also as a convenient vehicle for personal anger and an effective way to return to and correct the events perceived as traumatic and wrong.

Faraday is the first-person narrator of the novel and his point of view shapes the narrative and the information it provides. Well-mannered, rational and nice, Faraday, however, gradually reveals some of his darker emotions: anger and bitterness connected with his lower social position, disappointment with his life spent on hard work, the feeling of failure of his dreams, and the occasional hatred and envy of his neighbours. Perfectly natural and motivated, these emotions look mild enough and do not seem to influence the behaviour of the character and the plot of the novel; again, it is only gradually and indirectly that the link to the events of haunting and their disastrous effects become revealed. The growing sympathy and closeness of Faraday to the impoverished Ayreses and their once splendid residence, 
Hundreds Hall, is systematically accompanied by the disasters striking the family and the house. Starting with the accident with the dog Gyp biting a little girl and being put to death as a result; through the fire and the subsequent commitment to a psychiatric institution of the young master of the house, Roderick Ayres; to the suicide of Lady Ayres unable to mourn and live through the death of her baby-daughter; and ending with the surprising death or suicide of the last of the Ayreses, Caroline - all these events mark the development of and become milestones in the relationship between Dr Faraday and the Ayreses.

Interestingly, the dramatic visitations of the house and their disastrous results usually succeed episodes particularly unpleasant for Faraday: his feeling of being a second-class acquaintance during the party, his anger at Roderick's insults during the official dinner, or the rejection of his advances by Caroline. The fictional Faraday is constructed as a character too polite to express his anger and outrage openly; instead, his accumulated and suppressed hatred resurfaces within the narrative as a lethal energy which, through haunting and ghosts, wreaks havoc within the Ayreses house. Faraday's muted fury is aimed at the family which has been humiliating him and his family for a long time, but also at the house itself which embodies everything he has ever aspired to: class, sophistication, beauty and status, and which has been denied to him. His frustration with the house, his ambivalent feelings of admiration and the wish to destroy are in fact manifested quite early within the narrative, in a scene of his childish vandalisation of one of the house's ornaments. The gesture of chipping off a fragment of an ornament perfectly encapsulates, on the one hand, the admiration and wish to possess, and the anger at being rejected, on the other. Faraday's subsequent attitude towards the house is an extension and intensification of this childish ambivalence. Construed as an object of desire, the house provokes contradictory emotions explainable psychologically as a wish to unite with the desired object, and a simultaneous hatred towards it resulting from helplessness and dependence. The unresolved conflict and the ungratified desire find expression in the narrative haunting and both the destruction of and the unification with the house that it brings. The last scene of the novel vividly shows this ambivalent combination, with Faraday taking possession of the already empty house and thus commenting on its condition and his own feelings:

Wandering softly through the twilit spaces, I can even seem to see the house as its architect must have done when it was new, with its plaster detail fresh and unchipped, its surfaces unblemished. In those moments there is no trace of the Ayreses at all. It is as if the house has thrown the family off, like springing turf throwing off a footprint. . . If Hundreds Hall is haunted, however, its ghost doesn't show itself to me. For I'll turn, and am disappointedrealising that what I'm looking at is only a cracked window-pane, and that the face gazing distortedly from it, baffled and longing, is my own. (Waters, 2009, pp. 498-499)

Union and destruction, hatred, the wish to annihilate and admiration are intertwined within the character, dramatised by the plot of the novel as haunting, and embodied in the architectural space of the house. Haunting, then, becomes a fictional dramatisation of the complexities of desire and the anger whose roots lie in social inferiority and the frustrated wish to possess status and dignity. The negative energy of these feelings accumulates and becomes separated from the character, taking a fictional life of its own and emerging as 
haunting ghosts. Within the novel, they are referred to as poltergeists and described by one of the characters as "some sort of energy, or a collection of energies. . . They're not ghosts. They're parts of a person. Unconscious parts, so strong and troubled they can take on a life of their own" (Waters, 2009, p. 364). The fictional poltergeist in The Little Stranger, separated from its source, takes on the mission of exacting revenge for social injustice and gratifying the character's long-harboured desires. The social combines with the personal and explodes in a series of disastrous visitations that effectively wipe out the sources of both psychological and social discomfort.

Thus interpreted, haunting in Waters's novel may illustrate not merely the sociological, but also the psychological reading of spectrality as a textual expression and revisitation of a suppressed psychological - usually traumatic - content. The Little Stranger, even to a stronger degree than Affinity, captures the ambivalent, socio-psychological function of haunting and dramatises textually both the more general social ramifications of the position of lower classes, and their very real and palpable psychological consequences.

\section{Haunting as Political Intervention}

In both novels, then, haunting and spiritualism function at a number of levels. Aesthetically, they provide the narratives with interesting and attractive stories, plot twists and events that usually win the sympathy of readers. They introduce aspects relatively little known (e.g. the nineteenth-century female spiritualism) and offer a different perspective on the past (e.g. the post-war welfare state). More importantly, though, psychologically, they point to suppressed negative emotions of characters resulting from long-silenced traumas and serve as an expression of their anger and frustration. Finally, since at the root of the latter feelings lies the sense of social injustice caused by the British class structure and resistance to the resulting sense of inferiority, fictional haunting brings social and political matters to the fore, becoming a means to revisit and come to terms with the difficult and inglorious past.

Both novels show - via haunting - the revenge and retribution of the working class, exacted on the middle classes and aristocrats, for centuries of mistreatment, loathing and deprivation. Thus, Waters's novels become a clearly defined voice in the discussion of the past, revisiting it critically rather than nostalgically in a sharp contrast, for instance, to the tradition of the country-house novel. As Urszula Terentowicz-Fotyga observes, the English country house tends to be often represented — especially in the novel of manners which "defines the country house as 'a carrier of culture,' [and] a 'great good place"' (2015, p. 173) as a locus of specifically grand and noble ideals and values and a haven of "Englishness." Such portrayal tends to conveniently neglect the darker and less noble facts connected with the maintenance and success of such houses: the exploitation and mistreatment of the lower-class servants who operated them and who were treated with loathing and indifference. Waters's novels, in contrast, focus on the human costs involved in such projects and present and give voice to the so far little celebrated actors and experiences. 
Moreover, both novels, apart from showing the experience, attempt to imaginatively correct the wrongdoings of the past by presenting justice as it might have been dreamt of by the working classes. The texts offer them an opportunity - imaginary though it is - of exacting the revenge and setting the record straight. Haunting as a literary theme seems to be a convenient fictional vehicle for these goals, and, though somewhat surprisingly combined with political purposes, serves as a perfect tool to show the retribution of the underprivileged. Fictional spectres take on a political role of intervening into the discourses of the past and, via the imaginative correction they introduce, of changing the political status quo.

\section{References}

Fischer, S. A. (2013). 'Taking back the night'? Feminism in Sarah Waters' Affinity and Virginia Woolf's Night and Day. In K. Mitchell (Ed.), Sarah Waters: Contemporary critical perspectives (pp. 16-28). London: Bloomsbury.

Fleishman, A. (1971). The English historical novel: Walter Scott to Virginia Woolf. Baltimore, MD: Johns Hopkins University Press.

Gordon, A. F. (1997). Ghostly matters: Haunting and the sociological imagination. Minneapolis: University of Minnesota Press.

Hadley, L. (2010). Neo-Victorian fiction and historical narrative: The Victorians and us. Houndmills, UK: Palgrave.

Mukherjee, A. (2005). Missed encounters: Repetition, rewriting, and contemporary returns to Charles Dickens's Great Expectations. Contemporary Literature, 46(1), 108-133.

Owen, A. (1989). The darkened room: Women, power and spiritualism in late Victorian England. London, UK: Virago.

Parker, E. (2013). The country house revisited: Sarah Waters' The Little Stranger. In K. Mitchell (Ed.), Sarah Waters: Contemporary critical perspectives (pp. 99-113). London, UK: Bloomsbury.

Terentowicz-Fotyga, U. (2015). Competing genres in the English country house: The Little Stranger by Sarah Waters. In A. Kędra-Kardela \& A. Kowalczyk (Eds.), Expanding the Gothic canon: Studies in literature, film and new media (pp. 173-192). Frankfurt am Mein, Germany: Peter Lang.

Waters, S. (1999). Affinity. London, UK: Virago.

Waters, S. (2009). The little stranger. London, UK: Virago. 